\title{
Genetic Regulation of a Structural Polymorphism of Human C3b Receptor
}

\author{
Winnie W. Wong, James G. Wilson, and Douglas T. Fearon, Department of \\ Medicine, Harvard Medical School; Department of Rheumatology and \\ Immunology, Brigham and Women's Hospital, Boston, Massachusetts 02115
}

A B S T R A C T Two forms of the human C3b receptor (C3bR), which have relative molecular weights $\left(M_{\mathrm{r}}\right)$ of 250,000 and 260,000 and are designated $F$ and $S$, respectively, have been identified in specific immunoprecipitates from erythrocytes and leukocytes by polyacrylamide gel electrophoresis in the presence of sodium dodecyl sulfate. Both forms of the receptor were visualized on gels by autoradiography of ${ }^{125} \mathrm{I}$-labeled antigen and by silver nitrate staining. Individual donors expressed one of three possible patterns of $\mathrm{C} 3 \mathrm{bR}$, either the $\mathrm{F}$ or $\mathrm{S}$ form alone or both, and these patterns represented stable phenotypic characteristics of their erythrocytes and polymorphonuclear and mononuclear leukocytes. Removal of $N$-linked oligosaccharides by endoglycosidase- $F$ treatment decreased the $M_{\mathrm{r}}$ of both forms but did not abolish the difference in their electrophoretic mobilities. That both forms of the receptor were functional was indicated by the capacity of all antigenic C3bR sites on erythrocytes from individuals having any of the three phenotypes to bind dimeric $\mathrm{C} 3 \mathrm{~b}$ with affinities ranging from 3 to 5 $\times 10^{7} \mathrm{M}^{-1}$.

Analyses of the occurrence of the $F$ and $S$ forms of C3bR in 76 individuals from 15 families revealed that this polymorphism was regulated by two alleles transmitted in an autosomal codominant manner. Of 111 normal unrelated individuals, $64.9 \%$ were homozygous for the $F$ form (FF), $1.8 \%$ were homozygous for the $\mathrm{S}$ form (SS), and $33.3 \%$ were heterozygotes (FS). This distribution did not differ from that calculated by the Hardy-Weinberg equilibrium based on two codominant alleles that regulate the expression of the $F$ and $S$ forms and that have frequencies of 81.5 and $18.5 \%$,

After this work had been submitted, similar observations were reported independently (Dykman, T. R., J. L. Cole, K. Iida, and J. P. Atkinson, 1983, Proc. Natl. Acad. Sci. USA., 80:1698-1702).

Received for publication 6 October 1982 and in revised form 22 April 1983. respectively. The locus regulating structural polymorphism of C3bR is designated C3BRM (M for mobility or $M_{\mathrm{r}}$ ), and is distinct from the recently described locus regulating the quantitative expression of $\mathrm{C} 3 \mathrm{bR}$ on erythrocytes.

\section{INTRODUCTION}

The mammalian $\mathrm{C} 3 \mathrm{~b}$ receptor $(\mathrm{C} 3 \mathrm{bR}),{ }^{1}$ which is also termed CR 1 , was discovered almost $30 \mathrm{yr}$ ago, when human erythrocytes were observed to bind bacteria that had been treated with specific antibody and complement (1). Subsequently, the receptor was shown to be specific for $\mathrm{C} 3 \mathrm{~b}$, the major cleavage fragment of C3 produced during proteolysis by a C3 convertase, and for $\mathrm{C} 4 \mathrm{~b}$, the fragment produced by cleavage of $\mathrm{C} 4$ with $\mathrm{Cls}(2,3)$. Receptors having the same specificity were found to reside also on other cell types, including neutrophils, eosinophils, monocytes, macrophages, mast cells, B and some $T$ lymphocytes, and glomerular podocytes (4-10). Recently, the C3bR of human erythrocytes was purified to homogeneity and shown to be a glycoprotein with a relative molecular weight $\left(M_{r}\right)$ of 205,000 when assessed by polyacrylamide gel electrophoresis in the presence of sodium dodecyl sulfate (SDS-PAGE) (11). Monospecific rabbit antibody to this glycoprotein bound only to cell types that expressed C $3 \mathrm{bR}$ activity, inhibited the function of C3bR on erythrocytes, neutrophils, monocytes, and lymphocytes, and immunoprecipitated from each of these populations of cells a single membrane protein having a mobility on SDS-PAGE that was identical to that of the glycoprotein that had been isolated from erythrocytes $(8,12)$. Thus, the C3bR of these various human cell types is a common molecular entity, a con-

\footnotetext{
${ }^{1}$ Abbreviations used in this paper: C3bR, C3b receptor; DFP, diisopropylfluorophosphate; HBSS, Hanks' balanced salt solution; PAGE, polyacrylamide gel electrophoresis.
} 
clusion that is supported by recent studies using monoclonal antibodies $(13,14)$.

Specific antibodies to the C3bR and soluble forms of C3b have been used for the enumeration of cellular receptors $(12,13,15,16)$. The number of C3bR on human erythrocytes is regulated by two autosomal codominant alleles, tentatively designated $C 3 B R Q^{\circ} \mathrm{H}$ and $C 3 B R Q^{\circ} L$ according to a recommended standard nomenclature $(17,18)$, that determine the occurrence of three phenotypes in the normal population: a high phenotype, C3BRQ $\mathrm{H}(\mathrm{HH})$, having $>5,500$ antigenic receptor sites (representing $>600 \mathrm{C} 3 \mathrm{~b}$ binding sites) per erythrocyte, an intermediate phenotype, C3BRQ HL (HL), having 3,000-5,499 antigenic sites (350-600 $\mathrm{C} 3 \mathrm{~b}$ binding sites) per cell, and a low phenotype, C3BRQ L (LL), having $<3,000$ antigenic sites $(<350$ $\mathrm{C} 3 \mathrm{~b}$ binding sites) per cell (15). These three phenotypes were present in 34,54 , and $12 \%$, respectively, of normal individuals. A markedly different distribution was found for patients with systemic lupus erythematosus among whom 5,42 , and $53 \%$ had the $\mathrm{HH}$, HL, and LL phenotypes, respectively (15). This mode of genetic regulation of $\mathrm{C} 3 \mathrm{bR}$ expression was the basis of diminished numbers of erythrocyte receptors in lupus patients previously found by others $(13,19)$ and indicated that the abnormality in patients was inherited rather than secondarily acquired.

In the present study, a structural polymorphism of human $\mathrm{C} 3 \mathrm{~b}$ receptors is described that is detected by SDS-PAGE of the glycoprotein. Two variants of the receptor that differ by their $M_{\mathrm{r}}$ are identified and shown to be inherited in an autosomal codominant manner.

\section{METHODS}

Analysis of the C3b receptor by PAGE. Preparations of $5 \times 10^{6}$ purified human peripheral blood mononuclear or polymorphonuclear leukocytes $(20)$ and of $2 \times 10^{8}$ erythrocytes were each suspended in $1 \mathrm{ml}$ of Hanks' balanced salt solution (HBSS) (Gibco Laboratories, Grand Island, NY) and labeled with $1 \mathrm{mCi}$ of $\mathrm{Na}^{125}$ (New England Nuclear, Boston, MA) by a lactoperoxidase catalyzed reaction (21). The labeled cells were washed five times in ice-cold HBSS containing $0.1 \%$ bovine serum albumin (HBSS-BSA) and were incubated on ice for $20 \mathrm{~min}$ with $2 \mathrm{ml}$ of $0.5 \%$ Nonidet P40 in phosphate-buffered saline (NP-40-PBS) and $5 \mathrm{mM}$ diisopropylfluorophosphate (DFP). After removal of insoluble material by centrifugation of the detergent lysates at 44,000 $g$ for $30 \mathrm{~min}$ at $4^{\circ} \mathrm{C}$, the supernatants were each incubated sequentially with $50 \mu \mathrm{l}$ of nonimmune $\mathrm{F}\left(\mathrm{ab}^{\prime}\right)_{2}$-Sepharose and of $\mathrm{F}\left(\mathrm{ab} \mathrm{b}^{\prime}\right)_{2}$ anti-C $3 \mathrm{bR}$-Sepharose for $1 \mathrm{~h}$ at $4^{\circ} \mathrm{C}$. The Sepharose beads were washed once in NP-40-PBS and three times in Tris-buffered saline, $\mathrm{pH} 9.0$, containing $0.25 \%$ deoxycholic acid and $0.2 \%$ SDS, before the elution of adsorbed proteins by incubation for $3 \mathrm{~min}$ at $100^{\circ} \mathrm{C}$ in $100 \mu \mathrm{l}$ of $1 \% \mathrm{SDS}$. The eluted proteins were reduced and alkylated by incubation with $0.1 \mathrm{M}$ dithiothreitol and $0.2 \mathrm{M}$ iodoacetic acid and were analyzed by SDS-PAGE according to the method of Laemmli
(22) on slab gels of $1.5-\mathrm{mm}$ thickness and containing a gradient of $3-10 \%$ acrylamide. The gels were stained with Coomassie Blue, dried, and analyzed by autoradiography.

In an alternative procedure for analysis of the C3bR not involving the use of ${ }^{125} \mathrm{I}$, hemoglobin-free ghosts were prepared from erythrocytes by four washes in $40 \mathrm{vol}$ each of $5 \mathrm{mM}$ sodium phosphate $\mathrm{pH} 7.8$ containing $1 \mathrm{mM}$ phenylmethylsulfonylfluoride (Sigma Chemical Co., St. Louis, MO). The ghosts were used immediately or were stored at $-70^{\circ} \mathrm{C}$. Erythrocyte membrane proteins were extracted from the ghosts by addition of an equal volume of buffer containing $2 \% \mathrm{NP}-40,10 \mathrm{mM}$ sodium phosphate, $0.3 \mathrm{M} \mathrm{NaCl}$ (pH 7.4), and $5 \mathrm{mM}$ DFP (Sigma Chemical Co.) to preparations of $0.5-3.0 \mathrm{ml}$ packed ghosts. After incubation at $4^{\circ} \mathrm{C}$ for 20 $\mathrm{min}$, the insoluble material was removed by centrifugation of the detergent lysates at $44,000 \mathrm{~g}$ for $30 \mathrm{~min}$ at $4^{\circ} \mathrm{C}$. The supernatants were incubated with $50 \mu \mathrm{l}$ of $\mathrm{F}\left(\mathrm{ab}^{\prime}\right)_{2}$ anti-C $3 \mathrm{bR}$ Sepharose for $3 \mathrm{~h}$ at $4^{\circ} \mathrm{C}$ and the beads were washed and eluted according to the procedure described for the ${ }^{125} \mathrm{I}$-labeled immunoprecipitates. The eluates containing the C3bR were reduced, alkylated, and analyzed by SDS-PAGE on gradient gels of $0.75-\mathrm{mm}$ thickness. The positions of protein bands were detected by staining with silver nitrate (23). $M_{\mathbf{r}}$ markers used in SDS-PAGE included rabbit muscle myosin $\left(200,000 M_{\mathrm{r}}\right)$, phosphorylase $b\left(93,000 M_{\mathrm{r}}\right)$, BSA $\left(69,000 M_{\mathrm{r}}\right)$, ovalbumin $\left(43,000 M_{\mathrm{r}}\right)$, bovine carbonic anhydrase $(30,000$ $\left.M_{\mathrm{r}}\right)$, soybean trypsin inhibitor $\left(20,000 M_{\mathrm{r}}\right)$, and the human erythrocyte cytoskeletal proteins, band $1\left(240,000 M_{r}\right)$, band $2\left(220,000 M_{r}\right)$, and actin $\left(45,000 M_{r}\right)$.

Preparation of dimeric $C 3 b$, antibody to $C 3 b$ receptor, and immunoabsorbents. Purified $\mathrm{C} 3 \mathrm{~b}$, generated from native $\mathrm{C} 3$ by trypsin treatment, was cross-linked by incubation with a 20 -fold molar excess of dimethyl suberimidate (Aldrich Chemical Co., Milwaukee, WI) for $2 \mathrm{~h}$ at $30^{\circ} \mathrm{C}(15)$. The reaction mixture was subjected to centrifugation at $4^{\circ} \mathrm{C}$ for $16 \mathrm{~h}$ at $155,000 \mathrm{~g}$ on a linear gradient of $7.5-30 \%$ sucrose in veronal-buffered saline, and gradient fractions were analyzed for the presence of dimeric C3b by SDS-PAGE. Dimeric C3b was radiolabeled with ${ }^{125} \mathrm{I}$ to sp act $0.3 \mu \mathrm{Ci} / \mu \mathrm{g}$ with Iodo-Gen (Pierce Chemical Co., Rockford, IL) (24).

Affinity purified $F\left(a^{\prime}\right)_{2}$ anti-C3bR was prepared as previously described (15). The purified $F\left(a b^{\prime}\right)_{2}$ anti-C3bR and preimmunization $\mathrm{F}\left(\mathrm{ab}^{\prime}\right)_{2}$ were radiolabeled with ${ }^{125}$ I to specific activities ranging from 0.18 to $0.92 \mu \mathrm{Ci} / \mu \mathrm{g}(24) .1 \mathrm{mg}$ each of unlabeled nonimmune and immune $F\left(a^{\prime}\right)_{2}$ were coupled to $2 \mathrm{ml}$ each of $\mathrm{CNBr}$-activated-Sepharose to be used as immunoadsorbents.

Assays for $C 3 b$ receptors on erythrocytes. Erythrocytes from venous blood that had been anticoagulated with $10 \mathrm{mM}$ ethylenediamine tetraacetate and held at $0^{\circ} \mathrm{C}$ were washed twice in HBSS-BSA and were counted in a model ZF Coulter Counter (Coulter Electronics, Inc., Hialeah, FL). $2.5 \times 10^{8}$ erythrocytes were incubated for $60 \mathrm{~min}$ at $20^{\circ} \mathrm{C}$ in $0.2 \mathrm{ml}$ HBSS-BSA with $1.15 \mu \mathrm{g}$ of ${ }^{125} \mathrm{I}$-nonimmune $\mathrm{F}\left(\mathrm{ab}^{\prime}\right)_{2}$ or ${ }^{125} \mathrm{I}-$ $\mathrm{F}\left(\mathrm{ab}^{\prime}\right)_{2}$ anti-C3bR; this amount of anti-C $3 \mathrm{bR}$ yielded $97 \pm 0.9 \%$ (mean \pm SEM) saturation of antigenic sites on erythrocytes (15). Duplicate samples of cells in $0.075 \mathrm{ml}$ were removed from each reaction mixture, layered on $0.3 \mathrm{ml}$ dibutylphthalate (Eastman Organic Chemicals Div., Eastman Kodak Co., Rochester, NY) in $0.5 \mathrm{ml}$ polypropylene microfuge tubes, and pelleted by centrifugation at $8,000 \mathrm{~g}$ for $30 \mathrm{~s}$. The tubes were cut and the pellets and supernatants were assessed for bound and free antibody, respectively. The amount of nonimmune $F\left(a b^{\prime}\right)_{2}$ that was bound was subtracted from the amount of anti-C3bR that was taken up to obtain the specific binding data (15).

$2.5 \times 10^{8}$ erythrocytes were incubated for $60 \mathrm{~min}$ at $0^{\circ} \mathrm{C}$ 
in $0.2 \mathrm{ml} \mathrm{HBSS}$-BSA with incremental amounts ranging from 0.09 to $3 \mu \mathrm{g}$ of ${ }^{125} \mathrm{I}$-dimeric $\mathrm{C} 3 \mathrm{~b}$ alone or in the presence of $2 \mu \mathrm{g}$ unlabeled $F\left(a b^{\prime}\right)_{2}$ anti-C3bR. Bound and free ligand were separated by the method described for anti-C3bR. The amount of ${ }^{125} \mathrm{I}$-dimeric $\mathrm{C} 3 \mathrm{~b}$ that was bound in the presence of anti-C3bR was subtracted from that bound in the absence of antibody and specific binding was analyzed according to the method of Scatchard $(15,25)$.

Preparation of ${ }^{125} I-C 3 b R$ and endoglycosidase-F treatment. C3b receptor was purified from erythrocyte membranes of selected donors by modification of a previously described method (11). The membranes were solubilized in buffer with $10 \mathrm{mM}$ Tris, $150 \mathrm{mM} \mathrm{KCl}, 0.5 \% \mathrm{NP}-40,0.5 \%$ deoxycholate, and $2.5 \mathrm{mM}$ DFP and the detergent extracts were applied to a column of Matrix Red-A (Amicon Corp., Danvers, MA) at a starting ionicity of $12 \mathrm{mS}$ at $4^{\circ} \mathrm{C}$. After extensive washing, the adsorbed material was eluted with buffer containing $1 \mathrm{M} \mathrm{KCl}$. The fractions containing C3bR activity were further chromatographed on lentil lectin-Sepharose and C3b-Sepharose. The purified C3bR containing both $\mathrm{F}$ and $\mathrm{S}$ forms was dialyzed overnight at $4^{\circ} \mathrm{C}$ against 1 liter of borate buffered saline, $\mathrm{pH} 8.5$ with $0.25 \%$ NP-40 and $2 \mathrm{mM}$ DFP. The dialyzed receptor was labeled with ${ }^{125} \mathrm{I}$ by incubation for $90 \mathrm{~min}$ at $0^{\circ} \mathrm{C}$ with $250 \mu \mathrm{Ci}$ of ${ }^{125} \mathrm{I}$-BoltonHunter reagent and was chromatographed on Sephacryl S300 (Pharmacia Fine Chemicals, Piscataway, NJ) in PBS (pH 7.4) containing $0.25 \% \mathrm{NP}-40$ and $2 \mathrm{mM}$ DFP. A fraction containing $7 \mu \mathrm{Ci}$ was further applied to a $0.7 \times 50-\mathrm{cm}$ column of Sephacryl S-200 (Pharmacia Fine Chemicals) equilibrated in $100 \mathrm{mM}$ sodium phosphate, $50 \mathrm{mM}$ EDTA, $0.1 \%$ SDS, $2 \mathrm{mM}$ DFP, pH 6.1. The column fractions were screened for the presence of C3bR by analysis on SDS-PAGE and autoradiography. 2-Mercaptoethanol was added to 45 $\mu \mathrm{l}$ of a fraction containing $0.25 \mu \mathrm{Ci}$ and both $\mathrm{F}$ and $\mathrm{S}$ forms of $\mathrm{C} 3 \mathrm{bR}$ to achieve a final concentration of $1 \%$. The sample was heated in a boiling water bath for $5 \mathrm{~min}$ and was then made $1 \%$ in NP-40. $10 \mu \mathrm{l}$ of endoglycosidase-F (26) in 50 $\mathrm{mM}$ EDTA and $20 \%$ glycerol was added and the samples were incubated at $37^{\circ} \mathrm{C}$ for $0-5 \mathrm{~h}$. Small aliquots were removed at several intervals and diluted 40-fold in SDS-PAGE sample buffer to stop the reaction. Control experiments under identical conditions showed that endoglycosidase-F reduced the $M_{r}$ of $\alpha_{1}$-acid glycoprotein to that of its unglycosylated form, while having no effects on human serum albumin, a nonglycosylated protein, thus suggesting that its effect was not due to the presence of proteolytic enzymes. The endoglycosidase- $F$ used in these experiments was a generous gift of Dr. S. Alexander of the Scripps Research Institute, La Jolla, CA.

\section{RESULTS}

Peripheral blood erythrocytes and mononuclear and polymorphonuclear leukocytes from three representative normal donors were surface-labeled with ${ }^{125} I$ and the membrane proteins that were immunoprecipitated by nonimmune $F\left(a^{\prime}\right)_{2}$-Sepharose or $F\left(a^{\prime}\right)_{2}$ antiC3bR-Sepharose were analyzed by SDS-PAGE and autoradiography (Fig. 1). No radiolabeled material was observed in the control precipitates obtained with nonimmune $F\left(a b^{\prime}\right)_{2}$. Immune precipitates from each of the three cell types of donor A yielded a major band of radioactivity having an $M_{\mathrm{r}}$ of 250,000 , whereas the corresponding immune precipitates from donor $\mathrm{C}$

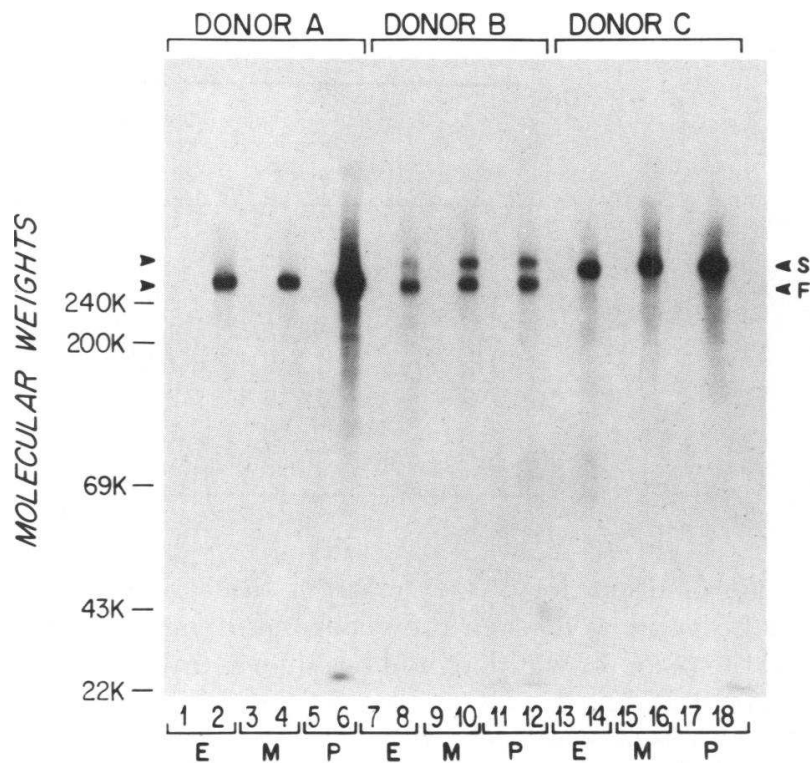

Figure 1 Autoradiographs of SDS-PAGE of ${ }^{125}$ I-labeled membrane proteins immunoprecipitated from erythrocytes $(E)$, mononuclear leukocytes $(\boldsymbol{M})$, and polymorphonuclear leukocytes $(P)$ of three representative individuals. Evennumbered lanes represent immunoprecipitates obtained with anti-C3bR and odd-numbered lanes represent the nonimmune controls.

yielded a major band of radioactivity having a higher $M_{\mathrm{r}}$ of 260,000 . Immune precipitates from donor B were composed of two radiolabeled bands of $M_{r}$ 250,000 and 260,000, which corresponded to the bands of donors $\mathrm{A}$ and $\mathrm{C}$, respectively. Reexamination of each donor over periods of at least 8 mo yielded identical results. Thus, the C3bR can exist in two forms, which are distinguished by their differential mobilities on SDS-PAGE, fast (F) and slow (S), and individuals can be classified as having either one or both of these forms.

The cells taken from donor B (Fig. 1) appeared to express more of the radiolabeled $\mathrm{F}$ than $\mathrm{S}$ form of the $\mathrm{C} 3 \mathrm{bR}$. To quantitate the relative expression of the $\mathrm{S}$ and $F$ forms of the C3bR among individuals having both forms, erythrocytes and neutrophils from donor $B$ and five other individuals were surface labeled with ${ }^{125} \mathrm{I}$ and labeled receptor was obtained by immunoprecipitation with $\mathrm{F}\left(\mathrm{ab}^{\prime}\right)_{2}$ anti-C3bR-Sepharose. After SDS-PAGE and autoradiography, the regions of the gels corresponding to the positions of the $\mathrm{F}$ and $\mathrm{S}$ forms were excised and assessed for the presence of ${ }^{125} \mathrm{I}$. Erythrocytes from donors B and J.C. had less radiolabeled S than F; these cells from M.M. and J.W. had equal amounts of the labeled forms of C3bR, and cells from A.H. and J.N. expressed more $S$ than F (Table I). Comparable relative expression of the $S$ and $F$ forms 
TABLE I

Relative Amounts of the S and F Forms of C3bR in Donors Expressing Both Forms

\begin{tabular}{|c|c|c|c|c|c|c|}
\hline \multirow[b]{2}{*}{ Donor } & \multicolumn{3}{|c|}{ Erythrocytes } & \multicolumn{3}{|c|}{ Neutrophils } \\
\hline & S & $\mathbf{F}$ & $\mathrm{S} / \mathrm{F}$ ratio & $\mathbf{S}$ & $\mathbf{F}$ & $S / F$ ratio \\
\hline & \multicolumn{2}{|c|}{$c p m$} & & \multicolumn{2}{|c|}{$c p m$} & \\
\hline B (Fig. 1) & 4,800 & 7,850 & 0.61 & 3,825 & 5,358 & 0.71 \\
\hline J.C. & 3,875 & 4,507 & 0.86 & 4,094 & 4,920 & 0.83 \\
\hline A.H. & 1,782 & 1,292 & 1.38 & 7,073 & 8,267 & 0.86 \\
\hline M.M. & 2,743 & 2,685 & 1.02 & 4,786 & 5,326 & 0.90 \\
\hline J.N. & 3,208 & 2,643 & 1.21 & 3,485 & 4,493 & 0.78 \\
\hline J.W. & 1,926 & 1,822 & 1.06 & 5,245 & 4,459 & 1.18 \\
\hline
\end{tabular}

of the C3bR on erythrocytes from these individuals was also observed when the experiment was repeated and the receptor was detected by silver nitrate staining of SDS-PAGE gels. The neutrophils of all six individuals also expressed both the $F$ and $S$ forms of C3bR. There was less variability of the ratio of $S$ to $F$ expression on neutrophils than on erythrocytes among the individuals, and in five of six instances, the amount of $F$ was slightly greater than that of $S$ (Table I).

The possibility that one of the forms of C3bR was generated from the other during the solubilization and immunoprecipitation of labeled cells was assessed in mixing experiments. ${ }^{125}$ I-labeled erythrocytes from donors $\mathrm{A}$ and $\mathrm{C}$ (Fig. 1) were mixed with unlabeled erythrocytes from the same or the other donor and were subjected to the standard solubilization and immunoprecipitation procedures. The mixing of labeled erythrocytes from donor A with unlabeled cells from donor $\mathrm{C}$ did not alter the $\mathrm{F}$ mobility of ${ }^{125} \mathrm{I}-\mathrm{C} 3 \mathrm{bR}$; similarly, the $\mathrm{S}$ electrophoretic mobility of ${ }^{125} \mathrm{I}-\mathrm{C} 3 \mathrm{bR}$ of donor $\mathrm{C}$ was not altered by the presence of erythrocytes from donor $A$.

A preparation of ${ }^{125}$ I-labeled C3bR containing both forms was treated with endoglycosidase-F for 0,2 , and $5 \mathrm{~h}$ at $37^{\circ} \mathrm{C}$ and then analyzed by SDS-PAGE. Addition of endoglycosidase- $\mathrm{F}$ without incubation did not alter the $M_{\mathrm{r}}$ of the $\mathrm{F}$ and $\mathrm{S}$ forms (Fig. 2), whereas incubation with the enzyme for 2 and $5 \mathrm{~h}$ decreased the $M_{\mathrm{r}}$ of both forms without altering the difference in their $M_{\mathrm{r}}$. Thus, $N$-linked carbohydrates do not appear to account for the structural difference between the two forms of C3bR.

The least complex genetic basis that can be proposed for this polymorphism of the C3bR assumes that the $\mathrm{F}$ and $\mathrm{S}$ forms are the products of two alleles at a single locus, which is tentatively designated C3BRM (for regulation of electrophoretic mobility or $M_{\mathrm{r}}$ ). According to this proposal, donors $\mathrm{A}$ and $\mathrm{C}$ (Fig. 1) would be homozygous for these alleles, having the C3BRM F
(FF) and C3BRM S (SS) phenotypes, respectively, and donor $B$ would be a heterozygote, having the phenotype C3BRM FS (FS).

The mode of inheritance of these phenotypes was assessed by examining the C3bR of erythrocytes from 116 unrelated normal individuals and 76 related individuals from 15 families. In these analyses, the C3bR was identified on polyacrylamide gels by staining with silver nitrate to avoid frequent radioiodination of cells. All three C3bR phenotypes could be recognized by the silver nitrate staining method (Fig. 3). Although con-

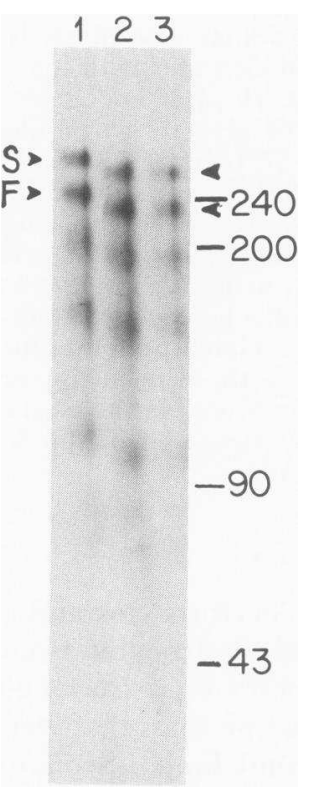

Figure 2 Autoradiograph of SDS-PAGE of endoglycosidase-F-treated ${ }^{125} \mathrm{I}-\mathrm{C} 3 \mathrm{bR}$. The $\mathrm{C} 3 \mathrm{bR}$ was purified from erythrocytes of individuals expressing the $F$ and $S$ forms. Lanes 1,2 , and 3 represent ${ }^{125} \mathrm{I}-\mathrm{C} 3 \mathrm{bR}$ after $0-, 2-$, or $5-\mathrm{h}$ incubations with endoglycosidase- $F$, respectively. The positions of C3bR are designated by arrow heads. 


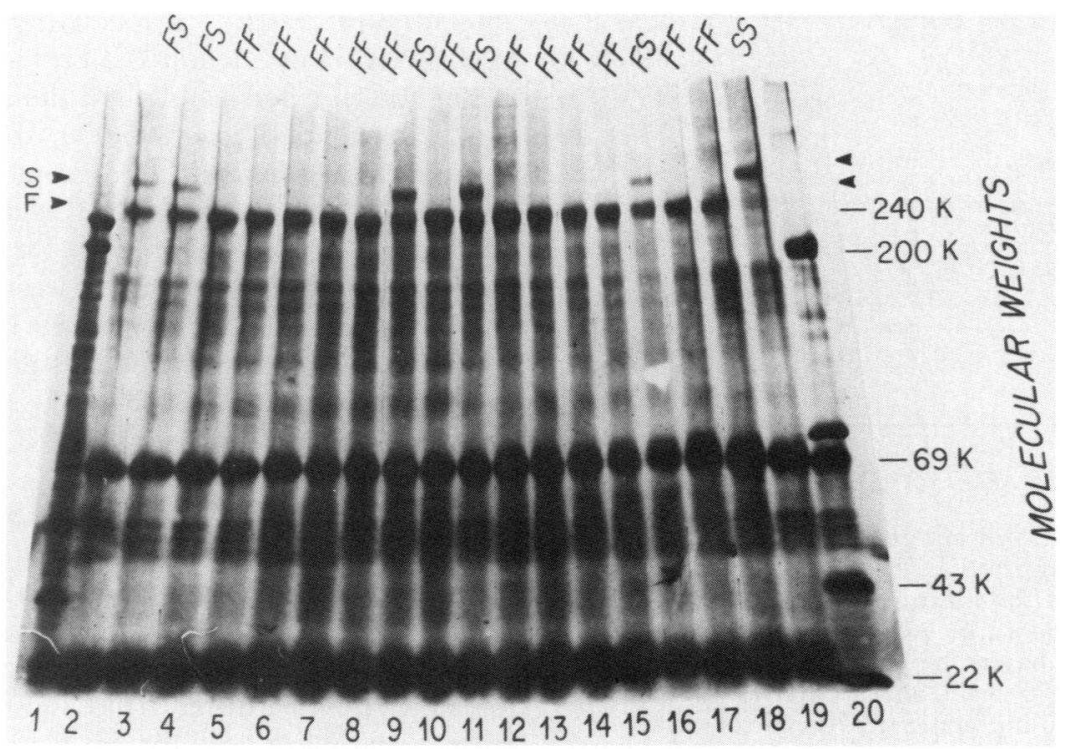

FIGURE 3 SDS-PAGE of anti-C3bR immunoprecipitates from erythrocytes of 18 normal individuals. Proteins were detected by staining with silver nitrate. Lane 1 contains proteins from erythrocyte membranes and lane 20 contains the $M_{\mathrm{r}}$ standards myosin, phosphorylase $b, \mathrm{BSA}$, ovalbumin, and carbonic anhydrase. The C3bR phenotype of each individual as determined by this method is designated by the symbols $F F, F S$, and $S S$ above the corresponding lanes. The positions of C3bR are designated by arrow heads.

taminating proteins were observed on these gels that were not detected by autoradiography (Fig. 3), these represented $\mathrm{BSA}$, which was present in the storage buffer for $F\left(a b^{\prime}\right)_{2}$ anti-C3bR-Sepharose, and heavy and light chains of the $F\left(a b^{\prime}\right)_{2}$ anti-C $3 b R$ that were released from the immunoadsorbent during elution by SDS. These contaminants and the unidentified minor bands of $M_{\mathrm{r}}$ of 100,000 to 180,000 did not interfere with C3bR identification. Repeat analysis by this procedure of 23,13 , and three individuals initially assigned the FF, FS, and SS phenotypes, respectively, confirmed these assignments.

The occurrence of the C3bR phenotypes in 116 unrelated normal individuals, of whom four were Asian and one was black, was studied by SDS-PAGE. The frequencies in men and women of FF, FS, and SS phenotypes were similar; one black individual had the SS phenotype and the four Asian persons had the FF phenotype. In the 111 white individuals, the calculated frequencies of the genes $C 3 B R M^{\circ} F$ and $C 3 B R M^{\circ} S$ were 81.5 and $18.5 \%$, respectively, and the observed frequencies of C3bR types and those expected from the Hardy-Weinberg equilibrium based on two codominant alleles did not differ $\left(\chi^{2}=1.258 ; 0.4>P\right.$ $>0.3$; Table II). In the family studies, four of the six possible combinations of parental phenotypes were available for analysis (Table III). The pattern of in- heritance of the C3bR phenotypes was consistent with an autosomal codominant mode of transmission.

The relationship of this structural polymorphism of C3bR to the number of C3bR expressed on erythrocytes was examined (Fig. 4). All three phenotypes of receptor number, $\mathrm{HH}, \mathrm{HL}$, and $\mathrm{LL}$, were found among individuals having the FF, FS, and SS structural phenotypes, respectively, suggesting that the structural polymorphism of C3bR has no major effects on quantitative expression. However, the number of antigenic sites per cell of individuals with the FF phenotype was

TABLE II

Observed and Expected ${ }^{\circ}$ C3b Receptor Phenotypes in Unrelated Caucasian Individuals

\begin{tabular}{llll}
\hline & FF & FS & SS \\
\hline Male $(n=65)$ & 42 & 22 & 1 \\
Female $(n=46)$ & 30 & 15 & 1 \\
Total $(n=111)$ & 72 & 37 & 2 \\
Observed frequency $(\%)_{\text {Expected frequency }^{\circ}(\%)}$ & 64.9 & 33.3 & 1.8 \\
\hline
\end{tabular}

- Based on the Hardy-Weinberg equilibrium $(p+q)^{2}$, where $p$ and $q$ represent observed gene frequencies. 


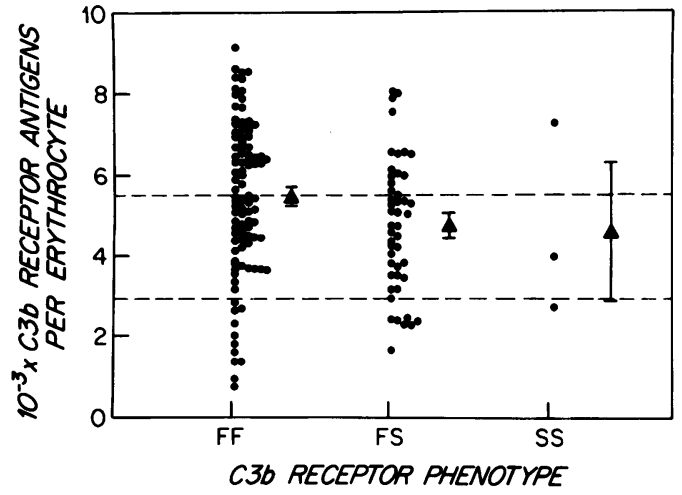

Figure 4 Number of C3bR antigenic sites on erythrocytes from individuals having the FF, FS, and SS structural phenotypes. Bars represent the mean $\pm S E M$ in each group. The dashed lines divide the three phenotypes of quantitative C3bR expression: $\mathrm{HH}$, having $>5,500$ antigenic sites/erythrocyte; $\mathrm{HL}$, having 3,000-5,499 antigenic sites/erythrocyte; and $\mathrm{LL}$, having $<3,000$ antigenic sites/erythrocyte.

$5,403 \pm 184$ (mean \pm SEM) and was slightly higher $(0.05$ $>P>0.03$ ) than the mean of $4,739 \pm 248$ sites/cell of persons with the FS phenotype. The infrequent occurrence of the SS phenotype did not allow reasonable determination of the mean number of erythrocyte receptors in this group.

The relative capacities of the $\mathrm{F}$ and $\mathrm{S}$ forms of C3bR to bind $\mathrm{C} 3 \mathrm{~b}$ were determined by comparing the uptake by erythrocytes of labeled $F\left(a b^{\prime}\right)_{2}$ anti-C $3 b R$ and dimeric C3b. Erythrocytes from 10 individuals having the FF receptor phenotype bound at saturation an average of $625 \mathrm{C} 3 \mathrm{~b}$ molecules and $5,762 \mathrm{~F}\left(\mathrm{ab}^{\prime}\right)_{2}$ antiC3bR molecules per cell, yielding a ratio of 9.2 antigenic sites per functional receptor. The average association constant of the receptor for dimeric $\mathrm{C} 3 \mathrm{~b}$ was $3.13 \pm 0.17 \times 10^{7} \mathrm{M}^{-1}$ (mean $\pm \mathrm{SEM}$ ). Erythrocytes from a single SS individual bound 509 C3b molecules and $4,632 \mathrm{~F}\left(\mathrm{ab}^{\prime}\right)_{2}$ anti-C3bR molecules per cell at saturation, yielding a ratio of 9.1 antigenic sites per functional receptor. This individual's erythrocyte receptors bound dimeric $\mathrm{C} 3 \mathrm{~b}$ with an association constant of 4.96 $\times 10^{7} \mathrm{M}^{-1}$. Erythrocytes from five FS individuals bound $470 \mathrm{C} 3 \mathrm{~b}$ molecules and $4,001 \mathrm{~F}\left(\mathrm{ab}^{\prime}\right)_{2}$ anti-C3bR molecules per cell, yielding a ratio of 8.5 antigenic sites per functional receptor, and receptors on these cells bound dimeric $\mathrm{C} 3 \mathrm{~b}$ with an association constant of $4.01 \pm 0.35 \times 10^{7} \mathrm{M}^{-1}$. Thus, there are no marked differences in the capacities of the $F$ and $S$ forms of the C3bR to bind soluble dimeric C3b.

\section{DISCUSSION}

The C3bR of peripheral blood erythrocytes and leukocytes exists in two forms, $F$ and $S$, that have $M_{r}$ of
250,000 and 260,000 , respectively, when assessed by SDS-PAGE (Figs. 1 and 3). Previous studies (11, 13, 27) of the purified C3bR had demonstrated only one band, having a $M_{\mathrm{r}}$ of 205,000 , that probably corresponded to the $F$ form because of the more frequent occurrence of individuals expressing only this form of C3bR. The higher $M_{r}$ of both forms of the C3bR in this study compared with the results of previous investigations from this laboratory is accounted for by differences in the analytical systems used and by the presence previously of NP-40 in samples that causes a more rapid migration of the C3bR on SDS-PAGE (data not shown).

The pattern of inheritance of the $F$ and $S$ forms of the receptor is consistent with autosomal codominant expression of two alleles (Table III). The observed frequencies of the FF, FS, and SS phenotypes in a population of 111 unrelated normal individuals selected for race did not differ from those predicted by the Hardy-Weinberg equilibrium based on gene frequencies of 0.81 and 0.19 for $C 3 B R M^{\circ} F$ and $C 3 B R M^{\circ} S$, respectively (Table II). These gene frequencies were calculated for the purpose of the Hardy-Weinberg analysis; actual gene frequencies in a larger population may vary slightly. When gels were overloaded, a small amount of immunoprecipitable material having the $M_{r}$ of the $\mathrm{F}$ form may be apparent in an SS individual (Fig. 1, lane 18, and Fig. 3, lane 19). This finding would not invalidate a genetic basis for the polymorphism, but would suggest the presence of two closely linked loci as for human $\mathrm{C4}$, with phenotypes being determined by varying expression of one or the other locus.

Although the structural polymorphism of C3bR appears to be genetically regulated, based on the family and population studies, another explanation for the appearance of two forms of the C $3 \mathrm{bR}$ is that they have a precursor-product relationship. According to this model, individuals having only the $S$ or $F$ form rep-

TABLE III

Inheritance of $F$ and $S$ Forms of C3b Receptor

\begin{tabular}{lcccc}
\hline & & \multicolumn{3}{c}{ Offspring phenotypes } \\
\cline { 3 - 5 } $\begin{array}{c}\text { Parental } \\
\text { phenotypes }\end{array}$ & $\begin{array}{c}\text { Number of } \\
\text { families }\end{array}$ & FF & FS & SS \\
\hline FF $\times$ FF & 4 & $17(17)^{\circ}$ & $0(0)$ & $0(0)$ \\
FF $\times$ FS & 8 & $9(10.5)$ & $12(10.5)$ & $0(0)$ \\
$F F \times$ SS & 2 & $0(0)$ & $4(4)$ & $0(0)$ \\
$F S \times$ SS & 1 & $0(0)$ & $0(2)$ & $4(2)$ \\
\hline
\end{tabular}

- Numbers in parentheses represent the expected phenotypes based on a two codominant allelic mode of inheritance. 
resent extremes of a continuum of conversion of $F$ to $S$ or of $S$ to $F$ and the variable ratios of the two forms among FS individuals represent varying completeness of conversion. However, this model would not readily explain either the inheritance of the $F$ and $S$ forms (Table III) or the close approximation between the observed frequencies of FF, FS, and SS individuals and those calculated by the Hardy-Weinberg equilibrium. In addition, this putative mechanism for postsynthetic conversion of one form of the receptor to the other would have to yield the same apparent phenotype in three separate cell types for each person (Fig. 1, Table I). Thus, a nongenetic mechanism accounting for the occurrence of two forms of the C3bR seems unlikely, but cannot be excluded without pulse-chase experiments of biosynthetically labeled C3bR.

The unequal expression of the two forms of C3bR on cells from FS individuals (Fig. 1, Table I) may indicate different rates of biosynthesis or catabolism of the $F$ and $S$ forms. The number of $\mathrm{C} 3 \mathrm{bR}$ molecules expressed on erythrocytes has been shown to be an inherited characteristic suggesting some mechanism for genetic regulation of biosynthesis. However, products of regulatory genes are usually not limited to a cis-effect. Moreover the variability in the relative amounts of $S$ and $F$ expressed by neutrophils of heterozygous individuals was less marked than that of erythrocytes. The latter cell type persists in the circulation for prolonged periods of time and its C3bR may be more subject to alterations by catabolism than are receptors on the relatively short-lived neutrophils. The absence of a consistent diminution on erythrocytes of one form of the receptor relative to the other suggests that differential rates of catabolism may not be the only basis for the variable S-to-F ratios on this cell type.

The structural polymorphism of the C3bR is unusual, because it can be detected by SDS-PAGE, whereas the demonstration of the polymorphic forms of the human serum complement proteins, C4, C2, C3, $\mathrm{C} 6, \mathrm{C} 8$, and factor $\mathrm{B}$ require procedures that separate proteins according to net charge rather than size (2833). Two forms of human C4 differing in their $M_{\mathrm{r}}$ have been described, but they represent products of two separate loci, $C 4 A$ and $C 4 B(34)$. Similar to the findings relating to the $\mathrm{C} 3 \mathrm{bR}$ are the allotypic $\alpha$-chain variants of murine $\mathrm{C} 4$ that can be distinguished by SDS-PAGE; these have been shown to differ in the extent of their glycosylation (35-37). Although we have shown that $N$-linked carbohydrates do not account for the difference in $M_{\mathrm{r}}$ of the $F$ and $S$ forms of the C3bR (Fig. 2), we have not determined whether there are differences in their primary sequence, $O$ linked carbohydrates, or both. However, the apparent codominant expression and cis-regulation of the C3bR forms do suggest that C $3 b R M$ is the locus of the C $3 b R$ structural gene.

Antigenically detectable C3bR on erythrocytes from individuals having the FF, FS, and SS phenotypes, respectively, bound dimeric $\mathrm{C} 3 \mathrm{~b}$ with a similar affinity, suggesting that the two forms of the receptor may not differ in function. However, other activities of the receptor, such as serving as cofactor for cleavage of $\mathrm{C} 3 \mathrm{~b}$ by factor I (11), facilitating phagocytosis (2), and mediating adsorptive endocytosis by polymorphonuclear leukocytes and monocytes (38) must be assessed before one can conclude that the two forms are functionally equivalent. Relevant to the possibility of variable function of these receptor allotypes differing by $M_{r}$ is the recent finding that the allotypic form of murine $\mathrm{C} 4$ having the lower $M_{\mathrm{r}} \alpha$-chain exhibits a $60-80 \%$ reduction in hemolytic activity (35).

The relationship between structural polymorphism and quantitative expression of the C3bR on human erythrocytes was examined to determine whether these two inherited characteristics were regulated by separate loci. The number of receptors as determined by binding of monospecific antibody to cells has been shown in two previous studies to correlate with a high degree of significance with the number of functional receptors $(15,39)$. All three structural phenotypes were found among individuals with high, intermediate, or low numbers of erythrocyte C3bR antigenic sites (Fig. 4), indicating that the gene, $C 3 B R M$, regulating structural polymorphism is distinct from that determining numbers of the C3bR. However, individuals with the FS phenotype had a slightly lower mean number of receptors than did persons with the FF phenotype, a finding that may be explained by the diminished expression of the $S$ form of the receptor relative to that of the $\mathbf{F}$ form in some heterozygous individuals (Figs. 1 and 3). Linkage of the loci regulating receptor structure and quantitative expression could not be reliably determined in this study, because only families in which one parent is homozygous and the other is heterozygous at both loci would be informative. In the single family having the necessary parental phenotypes, C3BRQ HL; C3BRM FS and C3BRQ H; C3BRM $F$, independent segregation of the alleles at these two loci was observed among the offspring.

The LL quantitative phenotype of erythrocyte C3bR expression is more prevalent among lupus patients than among normal individuals $(13,15,19)$. In addition, the receptor was absent from glomerular podocytes in lupus patients having severe proliferative nephritis in contrast to the apparently normal expression of glomerular receptors in other forms of lupus nephritis and nonlupus endocapillary nephritides (10). 
Since diminished quantitative expression of the C3bR appears to be related to the development of systemic lupus erythematosus, it will be essential to compare the two structural variants of the receptor for their relative functional capabilities and occurrence among patients with immune complex diseases.

\section{ACKNOWLEDGMENTS}

This investigation was supported by National Institutes of Health grants AI-07722, AI-17917, AM-05577, and RR05669 .

\section{REFERENCES}

1. Nelson, R. A., Jr. 1953. The immune adherence phenomenon. Science (Wash. DC). 118:733-737.

2. Gigli, I., and R. A. Nelson, Jr. 1968. Complement dependent immune phagocytosis. Exp. Cell Res. 51:45-67.

3. Cooper, N. R. 1969. Immune adherence by the fourth component of complement. Science (Wash. DC). 165:396-398.

4. Lay, W. H., and V. Nussenzweig. 1968. Receptors for complement on leukocytes. J. Exp. Med. 128:991-1007.

5. Reynolds, H. Y., J. P. Atkinson, H. H. Newball, and M. M. Frank. 1975. Receptors for immunoglobulin and complement on human alveolar macrophages. J. Immunol. 114:1813-1819.

6. Vranian, G., Jr., D. H. Conrad, and S. Ruddy. 1981. Specificity of C3 receptors that mediate phagocytosis by rat peritoneal mast cells. J. Immunol. 126:2302-2306.

7. Bianco, C., R. Patrick, and V. Nussenzweig. 1970. A population of lymphocytes bearing a membrane receptor for antigen-antibody-complement complexes. I. Separation and characterization. J. Exp. Med. 132:702-720.

8. Wilson, J. G., T. F. Tedder, and D. T. Fearon. 1982. Antigenic and functional detection of $\mathrm{C} 3 \mathrm{~b}$ receptors on human peripheral blood T lymphocytes. Fed. Proc. 41:965. (Abstr.)

9. Gelfand, M. C., M. M. Frank, and I. Green. 1975. A receptor for the third component of complement in the human renal glomerulus. J. Exp. Med. 142:1029-1034.

10. Kazatchkine, M. D., D. T. Fearon, M. D. Appay, C. Mandet, and J. Bariety. 1982. Immunohistochemical study of the human glomerular $\mathrm{C} 3 \mathrm{~b}$ receptor in normal kidney and in seventy-five cases of renal diseases. Loss of $\mathrm{C} 3 \mathrm{~b}$ receptor antigen in focal hyalinosis and in proliferative nephritis of systemic lupus erythematosus. $J$. Clin. Invest. 69:900-912.

11. Fearon, D. T. 1979. Regulation of the amplification C3 convertase of human complement by an inhibitory protein isolated from human erythrocyte membranes. Proc. Natl. Acad. Sci. USA 76:5867-5871.

12. Fearon, D. T. 1980. Identification of the membrane gly-, coprotein that is the $\mathrm{C} 3 \mathrm{~b}$ receptor of the human erythrocyte, polymorphonuclear leukocyte, B lymphocyte and monocyte. J. Exp. Med. 152:20-30.

13. Iida, K., R. Mornaghi, and V. Nussenzweig. 1982. Complement receptor $\left(\mathrm{CR}_{1}\right)$ deficiency in erythrocytes from patients with systemic lupus erythematosus. J. Exp. Med. 153:1427-1438.

14. Gerdes, J., M. Naiem, D. Y. Mason, and H. Stein. 1982. Human complement (C3b) receptors defined by a mouse monoclonal antibody. Immunology. 42:645-653.
15. Wilson, J. G., W. W. Wong, P. H. Schur, and D. T Fearon. 1982. Mode of inheritance of decreased C3b receptors on erythrocytes of patients with systemic lupus erythematosus. N. Engl. J. Med. 307:981-986.

16. Arnaout, M. A., J. Melamed, B. F. Tack, and H. R. Colten. 1981. Characterization of the human complement (C3b) receptor with a fluid phase C3b dimer. J. Immunol. 127:1348-1354.

17. Shows, T. B., C. A. Alper, D. Bootsma, M. Dorf, T. Douglas, T. Huisman, S. Kit, H. P. Klinger, C. Kozak, P. A. Lalley, D. Lindsley, P. J. McAlpine, J. K., McDougall, P. Meera Khan, M. Meisler, N. E. Morton, J. M. Opitz, C. W. Partridge, R. Payne, T. H. Roderick, P. Rubinstein, F. H. Ruddle, M. Shaw, J. W. Spranger, and K. Weiss. 1979. International system for human gene nomenclature (1979): ISGN (1979). Cytogenet. Cell Genet. 25:96-116.

18. Shows, T. B., and P. J. McAlpine. 1979. The 1979 catalog of human genes and chromosome assignments. Cytogenet. Cell Genet. 25:117-127.

19. Miyakawa, Y., A. Yamada, K. Kosaka, F. Tsuda, and M. Mayumi. 1981. Defective immune-adherence (C3b) receptor on erythrocytes from patients with systemic lupus erythematosus. Lancet. II:493-497.

20. Böyum, A. 1968. Isolation of mononuclear cells and granulocytes from human blood: isolation of mononuclear cells by one centrifugation, and of granulocytes by combining centrifugation and sedimentation at $\mathbf{l g}$. Scand. J. Clin. Lab. Invest. 21(Suppl. 19):77-89.

21. Morrison, M. 1974. The determination of the exposed proteins on membranes by the use of lactoperoxidase. Methods Enzymol. 32:103-109.

22. Laemmli, U. K. 1970. Cleavage of structural proteins during the assembly of the head of bacteriophage T4. Nature (Lond.). 227:680-685.

23. Oakley, B. R., D. R. Kirsch, and N. R. Morris. 1980. A simplified ultrasensitive silver stain for detecting proteins in polyacrylamide gels. Anal. Biochem. 105:361363.

24. Fraker, P. J., and J. C. Speck, Jr. 1978. Protein and cell membrane iodinations with a sparingly soluble chloroamide, 1,3,4,6 - tetrachlor - 3a,6a-diphenyglycoluril. Biochem. Biophys. Res. Commun. 80:849-857.

25. Scatchard, G. 1949. The attraction of proteins for small molecules and ions. Ann. NY Acad. Sci. 51:660-672.

26 . Elder, J. H., and S. Alexander. 1982. Endo- $\beta-N$-acetylglucosaminidase F: endoglycosidase from Flavobacterium meningosepticum that cleaves both high-mannose and complex glycopreteins. Proc. Natl. Acad. Sci. USA. 79:4540-4544.

27. Dobson, N. J., J. D. Lambris, and G. D. Ross. 1981. Characteristics of isolated erythrocyte complement receptor type one (CR $1, \mathrm{C} 4 \mathrm{~b}-\mathrm{C} 3 \mathrm{~b}$ receptor) and CR 1 specific antibodies. J. Immunol. 126:693-698.

28. Rosenfeld, S. I., S. Ruddy, and K. F. Austen. 1969. Structural polymorphism of the fourth component of human complement. J. Clin. Invest. 48:2283-2292.

29. Alper, C. A. 1976. Inherited structural polymorphism in human C2: evidence for genetic linkage between C2 and Bf. J. Exp. Med. 144:1111-1115.

30. Alper, C. A., and R. P. Propp. 1968. Genetic polymorphism of the third component of human complement (C'3). J. Clin. Invest. 47:2181-2191.

31. Hobart, M. J., P. J. Lachmann, and C. A. Alper. 1975. Polymorphism of human C6. Protides Biol. Fluids Proc. Colloq. 22:575-580. 
32. Raum, D., M. A. Spence, D. Balavitch, S. Tideman, A. D. Merritt, R. T. Taggart, B. H. Petersen, N. K. Day, and C. A. Alper. 1979. Genetic control of the eighth component of complement. J. Clin. Invest. 64:858-865.

33. Alper, C. A., T. Boenisch, and L. Watson. 1972. Genetic polymorphism in human glycine-rich beta-glycoprotein. J. Exp. Med. 135:68-80.

34. Roos, M. H., E. Mollenhauer, P. Demaut, and C. Rittner. 1982. A molecular basis for the two locus model of human component C4. Nature (Lond.). 298:854-856.

35. Karp, D. R., J. P. Atkinson, and D. C. Shreffler. 1982. Genetic variation in glycosylation of the fourth component of murine complement: Association with hemolytic activity. J. Biol. Chem. 257:7330-7335.

36. Roos, M. H., J. P. Atkinson, and D. C. Shreffler. 1978.
Molecular characterization of the Ss and Slp (C4) proteins of the mouse H-2 complex: subunit composition, chain size, polymorphism, and an intracellular (pro-Ss) precursor. J. Immunol. 121:1106-1115.

37. Parker, K. L., J. P. Atkinson, M. H. Roos, and D. C. Schreffler. 1980. Genetic and structural characterization of H-2 controlled allelic forms of murine C4. Immunogenetics. 11:55-63.

38. Fearon, D. T., I. Kaneko, and G. G. Thomson. 1981. Membrane distribution and adsorptive endocytosis by C3b receptors on human polymorphonuclear leukocytes. J. Exp. Med. 153:1615-1628.

39. Fearon, D. T., and L. A. Collins. 1982. Increased expression of $\mathrm{C} 3 \mathrm{~b}$ receptors on polymorphonuclear leukocytes induced by chemotactic factors and by purification procedures. J. Immunol. 130:370-375. 